\title{
An investigation on the effect of technology on total factor productivity improvement of insurance firms
}

\author{
Kambiz Peykarjou $^{\mathrm{a}}$ and Tahereh Malekshahi ${ }^{\mathrm{b}^{*}}$
}

${ }^{a}$ Assistant Professor, Department of Management and Economics, Science \& Research Branch, Islamic Azad University, Tehran, Iran ${ }^{b}$ Master of economy, Department of Management and Economics, Science \& Research Branch, Islamic Azad University, Tehran, Iran

\section{H R O N I C L E}

Article history:

Received December 2, 2013

Accepted 8 May 2014

Available online

May 282014

Keywords:

Productivity

Technology

Insurance firms

Total factor productivity

\begin{abstract}
A B S T R A C T
This paper presents an empirical investigation to study the impact of the implementations of the recent advances on technology on total factor productivity improvement (TFP) of some Iranian insurance firms over the period 2008-2012. The study considers the number of information and communication technology (ICT) employees, insurance treaty and the number of computers used together with online users as technology advancement. Using generalized least square technique, the study has determined a positive and meaningful impact of the number of research and development employees as well as the number of personal computers together with online users on TFP improvement. However, the numbers of ICT employees and insurance treaty have no significant impact on TFP improvement.
\end{abstract}

(c) 2014 Growing Science Ltd. All rights reserved.

\section{Introduction}

During the past few years, there have been tremendous changes on business organizations and there have been many giant organizations, which are solely built based on the magic of information and communication technology (Daly et al., 1985; Falk, 2005; Chambers \& Davies, 2001). Google, for instance, started its model in 1999 with only one million dollars but in less than 10 years, it became one of the biggest firms in terms of capital (Atzeni \& Carboni, 2006). Traditional business models such as banks, insurance firms, etc. have also tried to use the idea of information and communication technology to expand their businesses (Van Ark et al., 2003). There are also various studies on learning the effects of information and communication technology (ICT) on total factor productivity. Colombo et al. (2013) investigated the effect of the adoption of broadband Internet technology on the productivity performance of small and medium enterprises (SMEs). They reported that the effect of the adoption by SMEs of basic broadband applications was negligible (or even negative). Conversely,

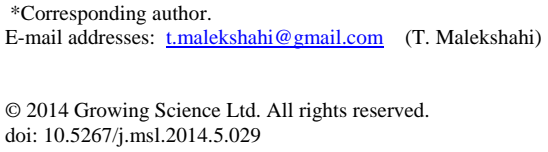


SMEs were detected to benefit from adopting selected advanced broadband applications depending on various contingent factors.

Hollenstein (2004) tried to explain timing and intensity of a firm's adoption of ICT using a large sample of firms. The analysis was based on the rank and the epidemic framework of technology adoption. The explanatory variables included various dimensions of anticipated advantages from and expenses of technology adoption, what provides to capture the effect of uncertainty and adjustment costs. They described the role of "New Workplace Organization" as a determinant of the adoption of ICT, as well as the reverse relationship. Jalava and Pohjola (2007) analyzed the effects of ICT on output and labor productivity growth in Finland over the period 1995-2005. They reported that ICT could be accounted for 1.87 percentage points of the observed labor productivity growth at the average rate of 2.87 per cent.

Neirotti and Paolucci (2007) investigated the insurance industry in the US and Europe through case studies and an analysis of 30 Italian insurance companies. Twenty case studies executed between 1998 and 2003 helped us conclude that technological and business path dependencies, along with time compression diseconomies, could result in diversities in IT adoption dynamics because of their differences in IT governance and management practice. The analysis also indicated that most of the insurance companies increased their productivity through IT regardless of their IT management capabilities. They also explained that competitive advantages were not associated with IT spending levels as well as with the type of IT investments that made general productivity growth in the industry possible.

\section{The proposed study}

This paper presents an empirical investigation to study the impact of the implementations of the recent advances on technology on productivity improvement of some Iranian insurance firms over the period 2008-2012.

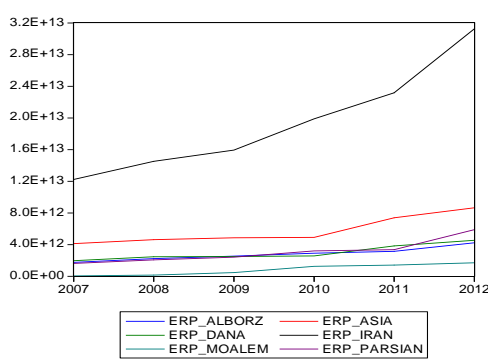

The earned premium

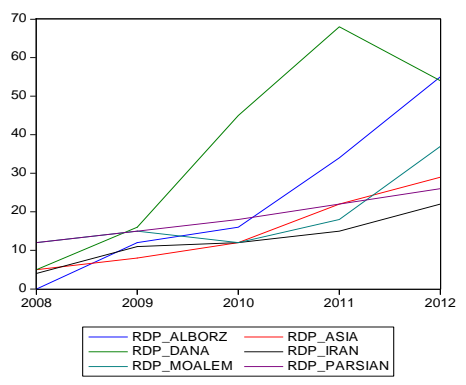

The number of R\&D employees

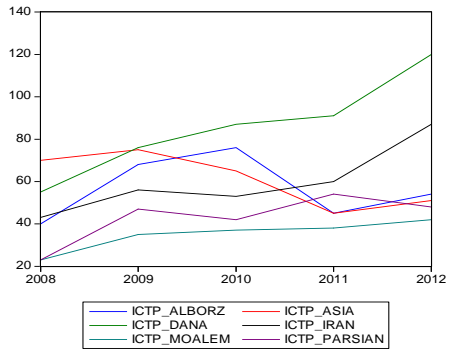

The number of ICT employees

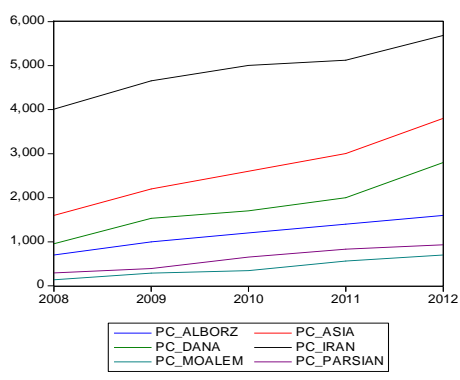

The number of PCs

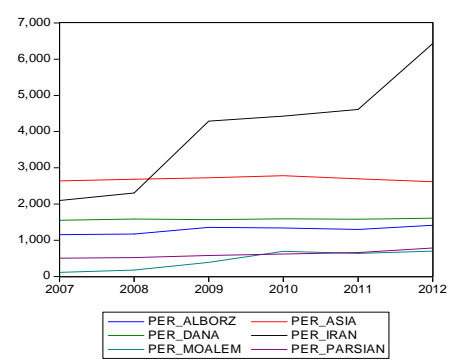

The number of total employees

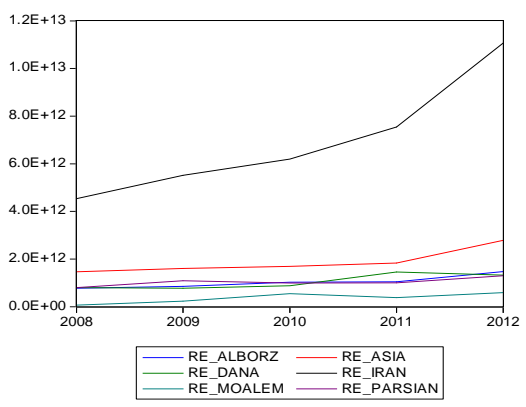

The amount of insurance treaty

Fig. 1. The trend of some basic statistics for six Iranian selected insurance firms

As we can observe from the results of Fig. 1, there is an increasing trend on the number of employees who were hired in this industry over the period 2008-2012. 
The study considers the number of information and communication technology (ICT) employees, insurance treaty and the number of computers used for online users as technology advancement. The study uses Cobb-Douglas method to measure the productivity using the following regression analysis,

$Y=A L^{\alpha} K^{\beta}$

where $L$ and $K$ represent labor, capital, respectively. In addition, $Y$ demonstrates value added and $A, \alpha$ and $\beta$ are coefficients, which are estimated using regression analysis. The proposed study uses the following form of Cobb-Douglas function,

$$
E R P_{i t}=A_{i} * I N L O S_{i t}^{\alpha} * P E R_{i t}^{\beta} * B R A_{i t}^{\gamma} * A G E_{i t}{ }^{\lambda}
$$

Taking the natural logarithm on Eq. (2) yields,

$$
L E R P_{i t}=\alpha L I N L O S_{i t}+\beta L P E R_{i t}+\gamma L B R A_{i t}+\lambda L A G E_{i t}+\varepsilon_{i t}
$$

where ERP represents earned premium of insurance, INLOS is incoming losses, $P E R$, stands for the number employees, $B R A$ states the number of branches and finally, $A G E$ shows total number of agents. In order to find out whether we have to use fixed effect or random effect as well as learning Pooled Least Squares we use F-test, which is equal to $\mathrm{F}=7.6032$ with P-value $=0.0002$. Therefore, we use fixed effect for the proposed study of this paper. We have also used Hausman Test and the Chi-Square value is equal to 33.950 with P-value $=0.000$. In addition, the study uses Generalize Least Square(GLS) instead of Pooled least square technique.

We present details of our findings by applying GLS technique on two regression models. The results of the first mode is as follows,

\section{Table 1}

The summary of regression analysis of LERP as a function of LINLOS, LPER, LAGE and LBRA

\begin{tabular}{cccc}
\hline Variable & Coefficient & t-value & P-value \\
\hline C & 13.98 & 13.075 & 0.000 \\
LINLOS & 0.199 & 2.97 & 0.0064 \\
LPER & 0.8108 & 4.22 & 0.0003 \\
LAGE & 0.261 & 1.926 & 0.0651 \\
LBRA & 0.387 & 2.58 & 0.0158 \\
\hline $\mathrm{R}^{2}=0.987 \quad \overline{\mathrm{R}^{2}}=0.983$ & D.W $=1.398$ & &
\end{tabular}

According to the results of Table 1, we may summarize the results in Eq. (2) as follows,

$$
L E R P=13.98+0.199 L I N L O S+0.810 L P E R+0.261 L A G E+0.387 L B R A
$$

Based on the results of Table 1, we can understand that employees influence on earning premium more than other variables do. In addition, the number of branches is the second most efficient factors on ERP. We now present details of our findings on total factor productivity (TFP) in Eq. (3) as follows,

$$
\mathrm{TFP}=\beta_{0}+\beta_{1} L_{I C T P} P_{i t}+\beta_{2} L R D P_{i t}+\beta_{3} L R E_{i t}+\beta_{4} L O G\left(P C_{i t} * O N L I N_{i t}\right)+U_{i t}
$$

where LICTP represents natural logarithm of the number of ICT employees, LRDP demonstrates the amount of investment on research and development, $L R E$ represents the logarithm of the amount of insurance treaty, $P C$ represents the number of personal computer and $O N L I N$ states the number of online users. Similarly, In order to find out whether we have to use fixed effect or random effect as well as learning Pooled Least Squares we use F-test, which is equal to $\mathrm{F}=1.552$ with $\mathrm{P}$-value $=0.221$. Therefore, we have used fixed effect for the proposed study of this paper. Table 2 shows the summary of regression analysis on Eq. (3) as follows, 
Table 2

The summary of regression analysis of LERP as a function of LINLOS, LPER, LAGE and LBRA

\begin{tabular}{cccc}
\hline Variable & Coefficient & t-value & P-value \\
\hline C & 1.167 & 2.413 & 0.0238 \\
LICTP & -0.278 & -4.821 & 0.0001 \\
LRDP & 0.1006 & 3.668 & 0.0012 \\
LRE & -0.044 & -2.425 & 0.0232 \\
LOG(PC $\times$ ONLIN) & 0.101 & 3.928 & 0.0006 \\
\hline
\end{tabular}

$\mathrm{R}^{2}=0.656 \quad \overline{\mathrm{R}^{2}}=0.599 \quad \mathrm{D} . \mathrm{W}=2.018$

According to the results of Table 2, the number of online users together with number of personal computers has the highest impact on total factor productivity followed by the amount of research and development spent on development of business units. In addition, all statistical observations such as tstudent values and Durbin-Watson value are within acceptable limits. The result of R-Square indicates that the independent variables could approximately describe $60 \%$ of the changes on TFP.

\section{Conclusion}

During the last few years, there have been tremendous changes on development of technology and most organizations take advantage of the recent advances on information technology, personal computers, etc. to increase the productivity of their organizations. In this survey, we have presented an empirical investigation to examine the effects of different factors on productively improvement in insurance firms. The results of our studies have confirmed that the number of online users together with the number of personal computers has the highest impact on total factor productivity followed by the amount of research and development spent on development of business units.

\section{Acknowledgement}

The authors would like to thank the anonymous referees for their comments.

\section{References}

Atzeni, G. E., \& Carboni, O. A. (2006). ICT productivity and firm propensity to innovative investment: evidence from Italian microdata. Information Economics and Policy, 18(2), 139-156.

Van Ark, B., Inklaar, R., \& McGuckin, R. H. (2003). Changing gear: Productivity, ICT and service industries: Europe and the United States. The Industrial Dynamics of the New Digital Economy, Edward Elgar, 56-99.

Chambers, A., \& Davies, G. (Eds.). (2001). ICT and language learning: a European perspective. Lisse, The Netherlands: Swets \& Zeitlinger.

Colombo, M. G., Croce, A., \& Grilli, L. (2013). ICT services and small businesses' productivity gains: An analysis of the adoption of broadband Internet technology. Information Economics and Policy, 25(3), 171-189.

Daly, M. J., Someshwar Rao, P., \& Geehan, R. (1985). Productivity, scale economies and technical progress in the Canadian life insurance industry. International Journal of Industrial Organization, 3(3), 345-361.

Falk, M. (2005). ICT-linked firm reorganisation and productivity gains. Technovation, 25(11), 12291250.

Hollenstein, H. (2004). Determinants of the adoption of information and communication technologies (ICT): an empirical analysis based on firm-level data for the Swiss business sector. Structural change and economic dynamics, 15(3), 315-342.

Jalava, J., \& Pohjola, M. (2007). ICT as a source of output and productivity growth in Finland. Telecommunications Policy, 31(8), 463-472.

Neirotti, P., \& Paolucci, E. (2007). Assessing the strategic value of Information Technology: An analysis on the insurance sector. Information \& Management,44(6), 568-582. 